\title{
TRANSFORMACIONES EN LA ORGANIZACIÓN AGRÍCOLA DE PEQUEÑOS PRODUCTORES DEL VALLE CALCHAQUÍ NORTE (DEPARTAMENTO DE CACHI, SALTA)
}

\author{
TRANSFORMATIONS IN THE AGRICULTURAL ORGANIZATION OF SMALL \\ PRODUCERS OF VALLE CALCHAQUÍ NORTE (CACHI, SALTA)
}

\author{
Gimena Alé Marinangeli y María Cecilia Páez*
}

\begin{abstract}
La organización productiva agropecuaria de Cachi (Salta, Argentina) se ha reconfigurado a partir de nuevas formas de producción asociadas a demandas del mercado. Una de ellas ha sido el ingreso del cultivo de pimiento para pimentón alrededor de 1940, que reorientó la producción comercial hacia la horticultura y posicionó a los valles calchaquíes como la principal región productora del país. Posterior a la década de 1970, el auge de las políticas neoliberales en Argentina promovieron la presencia de nuevos actores, como es el caso del turismo y los emprendimientos vitivinícolas, que conducen a reconfigurar la arena socioeconómica local. En este trabajo nos proponemos analizar las transformaciones que estos factores asociados al mercado generan en las configuraciones agrícolas locales de Cachi (Salta), tomando como referente temporal la segunda mitad del siglo XX. Para ello se trabajará a partir de registros etnográficos, datos censales y fuentes bibliográficas, procurando introducir una discusión que se articule con las realidades vivenciadas en la escena regional. Los primeros resultados alertan acerca de la disminución de las formas colectivas de trabajo de la tierra y propiedad de los medios de producción, así como de modificaciones en el tipo y formas de cultivo atendiendo a las demandas del mercado. Un elemento central en este análisis está dado por la creciente concentración territorial que opera a favor de los sectores que concentran el capital económico en la región.
\end{abstract}

Palabras claves: Prácticas agrícolas, unidad productiva familiar, mercado, Estado, Cachi.

The agricultural productive organization of Cachi (Salta, Argentina) has been reconfigured from new forms of production associated with market demands. One of these has been the entry of the pepper crop for paprika around 1940, which reoriented commercial production towards horticulture and positioned the Calchaqui valleys as the main producing region of the country. After the 1970s, the rise of neoliberal policies in Argentina promoted the presence of new actors, as is the case of tourism and vitivinicultural undertakings, which lead to reconfiguring the local socio-economic arena.

In this paper we propose to analyze the transformations that these factors associated to the market generate in the local agricultural configurations of Cachi (Salta) taking as a temporal reference the second half of the 20th century. To do this, we will work from ethnographic records, census data and bibliographic sources, trying to introduce a discussion that is articulated with the realities experienced in the regional scene. The first results warn about the abandonment of the collective forms of work of the land and property of the means of production, as well as modifications in the type and forms of cultivation attending to the demands of the market. A central element in this analysis is given by the growing territorial concentration that operates in favor of the sectors that concentrate economic capital in the region.

Key words: Agricultural practices, family productive unit, market, State, Cachi.

\section{Introducción}

El departamento de Cachi se encuentra al centro-oeste de la provincia de Salta, República Argentina (Figura 1). Está conformado por los municipios de Cachi y Payogasta, con dichas localidades como cabeceras, y varios parajes que se caracterizan por su gran proporción de población rural -64\%- (Dirección General de Estadísticas de Salta 2013). Integra una zona agroeconómica homogénea denominada Valle Calchaquí Salteño (Instituto Nacional de Tecnología Agropecuaria [INTA] 2008), cuyas actividades principales se orientan a las labores agropecuarias, siendo preponderante la agricultura bajo riego y, en menor medida, la ganadería de ovinos y caprinos como complemento de las economías familiares (Cieza 2010, Manzanal 1987, Obschatko et al. 2007, Pais 2011). La situación de inequidad en la distribución de la propiedad de la tierra que caracteriza la zona

* Universidad Nacional de La Plata, Facultad de Ciencias Naturales y Museo, División Arqueología, La Plata, Buenos Aires, Argentina. Correo electrónico: gimemarinangeli@gmail.com; ceciliapaez@gmail.com 


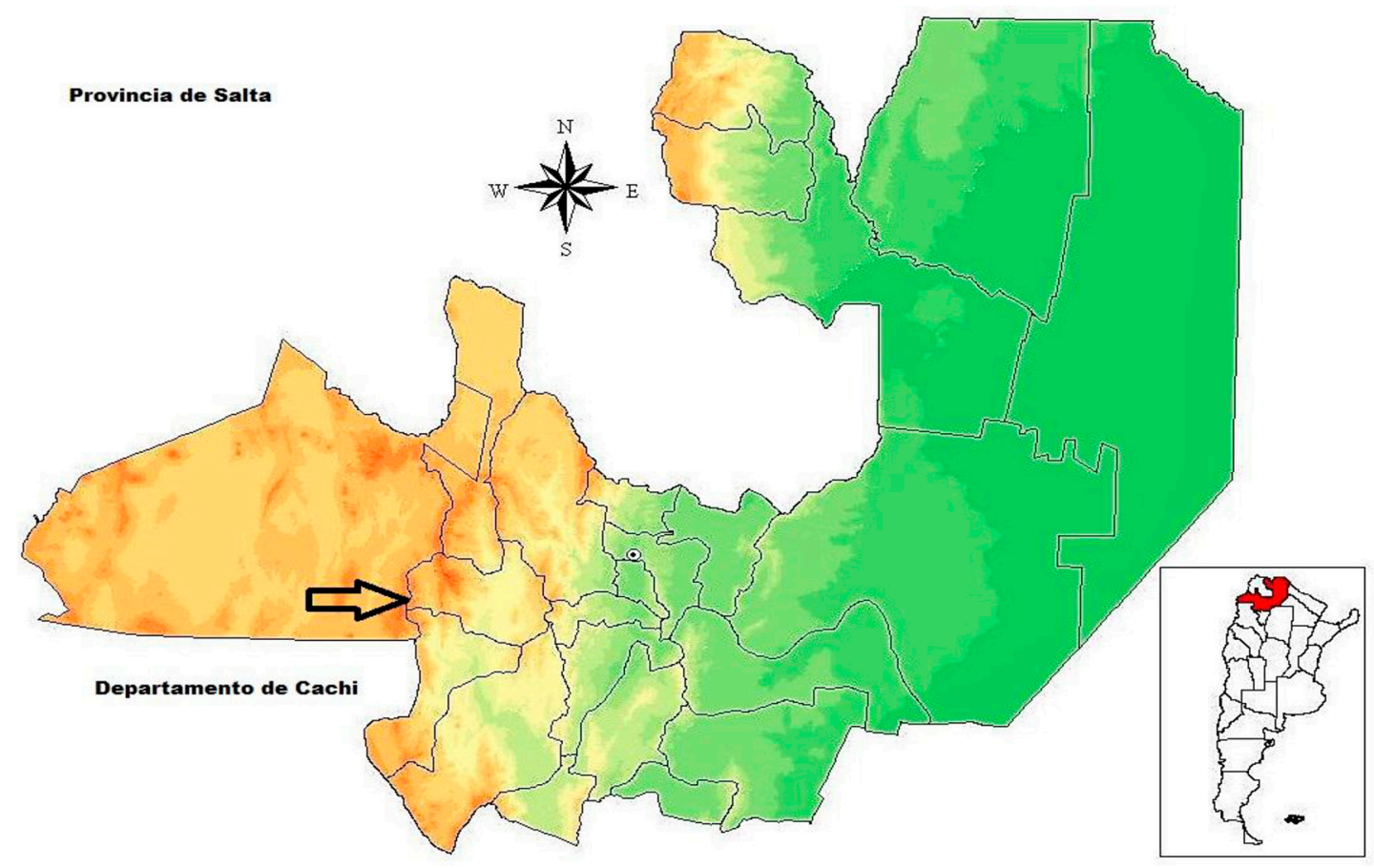

Figura 1. Modificado por las autoras a partir del mapa extraído de EduSalta (Ministerio de Educación, Ciencia y Tecnología 2014).

proviene de la conformación de grandes latifundios coloniales organizados en haciendas o fincas durante el periodo nacional (Lera 2005, Mata de López 2005). Una de ellas, la Finca Hacienda de Cachi, tiene su origen al fin de la etapa colonial y es particularmente relevante, debido a su gran extensión -llegó a abarcar a fines del siglo XIX gran parte del municipio de Cachi- y la preponderancia que adquirió para la configuración de la localidad de Cachi durante la organización del Estado (Lera 2005). Esta finca fue expropiada por parte del gobierno provincial en 1949 y mediante un proceso que duró 8 años hasta 1957, ocasionó la expansión de los límites jurisdiccionales de Cachi pero fundamentalmente el acceso a la propiedad de la tierra por parte de más de cien de sus arrendaderos al fragmentarse en parcelas rurales de entre 4 y 8 hectáreas (Lera 2005, Lanusse 2007, Pais 2011). Este proceso fue representativo para la conformación de la estructura agraria de la zona que, sin embargo, continúa siendo muy desigual y se caracteriza por una gran cantidad de explotaciones agropecuarias menores a 10 hectáreas a cargo de pequeños productores, mientras que la mayor cantidad de superficie está concentrada en grandes fincas de unos pocos dueños (Manzanal 1987, Pais 2011).
Por otro lado, la expropiación motivó la participación directa de los arrenderos de la finca en la comercialización de los cultivos de renta, que estaba circunscrita en sus inicios principalmente a las grandes haciendas de la zona, para poder pagar la propiedad de su tierra. También accedieron a la compra de parcelas productores que no eran arrenderos de la finca y comenzaron a producir para el mercado (Pais 2011). De esta manera, los productores se orientaron a la comercialización de pimiento para pimentón-Capsicum annuum var. аппиит - como principal cultivo de renta, que era una producción reciente en ese momento y de gran importancia, ya que hacia mediados del siglo XX reemplaza la comercialización de ganado vacuno como actividad central (Manzanal 1995). La presencia de agricultura comercial, no obstante, no desplaza las prácticas de autoconsumo (Pais 2011), cuyo objetivo primordial es reproducir las unidades productivas más que acumular excedentes (Llambí 1981, Mayer 2004, Shanin 1976).

Por otro lado, el impacto del mercado ha generado en la región una creciente concentración territorial y aumento de conflictos por el territorio, sumado a las intervenciones del Estado para incentivar dichas actividades económicas. Estos procesos 
han sido registrados con detalle para el área sur de los valles calchaquíes salteños -departamentos de Cafayate y San Carlos-, y se vinculan de manera directa con la profundización del neoliberalismo instaurado en nuestro país a partir de la década de 1970 y profundizado hacia 1990 (Cáceres 2018, Cáceres y Troncoso 2014, Vázquez 2014, Vázquez y Aguilar 2014, Villagrán 2013, 2014).

En este marco contextual, nos proponemos analizar la organización agrícola familiar, considerando su devenir histórico y las prácticas locales en interrelación con factores provenientes de los procesos de cambio que ha atravesado la región, particularmente la intensificación del mercantilismo agrícola, aspectos de la distribución de la propiedad de la tierra y la irrupción de nuevos actores en la escena regional en consonancia con las políticas neoliberales postdécada del 90 en Argentina. Se establece como límite temporal el momento en que los pequeños productores adquieren mayor participación en el mercado hortícola regional -a partir de 1940-, para analizar las reconfiguraciones en las prácticas agrícolas a partir de una mayor presencia directa del mercado. Para abordar estas cuestiones se partió de un diseño metodológico cualitativo basado en técnicas documentales de revisión bibliográfica para procurar contextualizar procesos históricos y regionales, se consultaron fuentes documentales censales para precisar datos productivos y de tenencia de la tierra en el área; y en particular se acudió a información construida en trabajos de campo etnográficos desarrollados por nuestro equipo de investigación desde $2014^{1}$ en Cachi. En este marco se desarrollaron en principio conversaciones informales y entrevistas abiertas ${ }^{2}$ como estrategias comunicativas a partir de las cuales se establecieron diversas categorías descriptivas y significaciones de los sujetos en tanto actores sociales (Guber 2001). Asimismo, se desarrollaron entrevistas en profundidad ${ }^{3}$ a personas vinculadas con la agricultura de las localidades de Cachi y Payogasta y sus áreas rurales de influencia. Por su parte, participar en las labores agrícolas de los interlocutores y compartir actividades cotidianas posibilitó la construcción conjunta y participativa de las perspectivas y sentidos sostenidos por los sujetos, así como conocer la rememoración de ciertas prácticas y los conflictos y tensiones que se viven en la actualidad.

Para su delimitación analítica, en la investigación se utilizó la categoría pequeños productores agropecuarios. Si bien agrupa un conjunto heterogéneo de actores, este encuadre nos parece apropiado para no encasillar a los sujetos en categorías teóricas con las que no se sienten identificados. Los elementos de confluencia de dicho concepto giran en torno a la importancia del trabajo familiar en las unidades productivas, una determinada dotación de tierra, capital y tecnología, la falta de empleo de trabajadores no familiares de manera permanente y una escasa o nula acumulación de excedentes (Carballo et al. 2004, Obschatko et al. 2007, Tsakoumagkos et al. 2000). Es remarcable que las categorías de pequeños productores y agricultores familiares con las que se autoidentifican los interlocutores consultados provienen de categorizaciones provistas por el Estado, a partir de las políticas de gestión de los programas provinciales y nacionales.

\section{Contextualización histórica de las actividades agropecuarias en la región}

Las labores asociadas a la producción agrícola y ganadera han sido muy extendidas en los valles calchaquíes desde tiempos prehispánicos (Baldini y Villamayor 2007, Castellanos 2016, Páez et al. 2012, Williams et al. 2011). Las evidencias arqueológicas de los sitios presentes en la zona dan cuenta de la prevalencia de grandes superficies de cultivo -canchones-asociadas a los poblados, estructuras de andenes, sistemas de irrigación, recintos para el almacenamiento de productos; además de corrales y otras evidencias de crianza y pastoreo de animales (Díaz 1983, Lanusse 2007, Páez y Giovannetti 2014, Páez et al. 2012, Páez et al. 2014, Páez y López 2016, Prieto et al. 2012, Raffino y Baldini 1983, Tarragó 1974, 1977, Tarragó y Díaz 1972, Tarragó y De Lorenzi 1976, Williams et al. 2011, Williams y Castellanos 2014).

Cuando los españoles irrumpieron en el área a mediados del siglo XVI, las actividades productivas principales de los pueblos indígenas eran la agricultura bajo riego complementada por el pastoreo de llamas y guanacos (Mata de López 2005). El gran desarrollo de su sistema agrícola posibilitaba la producción de variados cultivos como papa, maíz, quinua, legumbres, algarroba, chañar, etc. (Mata de López 2005). Estas poblaciones locales resistieron por más de 130 años la conquista hispana, proceso denominado "guerras calchaquíes" (Lorandi \& Boixadós 1987-1988). Al finalizar, 
en la segunda mitad del siglo XVII, los colonos españoles se orientaron al cultivo de vid y trigo en las mercedes de tierras que les fueron otorgadas por su participación en la conquista, explotando la mano de obra indígena que obtuvieron mediante la institución de la encomienda. Sobre esta base, en el siglo XVIII se constituyen las haciendas como sistema económico, caracterizado por extensas superficies de tierra destinadas a la producción agrícola o ganadera para abastecer al mercado (Mata de López 2005). Así, y posteriormente con la organización del Estado, se consolida la propiedad privada en el valle y se constituyen circuitos mercantiles que van especializando la producción de las distintas áreas (Mata de López 2005). Las labores de los trabajadores en las haciendas eran retribuidas con la concesión de arriendos, en los que la unidad doméstica desarrollaba la producción para autoconsumo (Hocsman 2003, Pais 2011). Lanusse (2007) analiza la especificidad de estos arreglos en haciendas de la zona -particularmente los de la Finca Palermo Oeste, en el departamento de Cachi-. Así, da cuenta de que en general, los arreglos en el siglo XIX y principios del siglo XX consistían en pagos al patrón a cambio de un terreno que les permitía construir sus hogares y contar con una producción agropecuaria de subsistencia; o en otros casos, trabajar una quincena para el patrón a cuenta del alquiler de dicho espacio.

En este marco, los cultivos de cereales como el maíz y el trigo adquirieron gran desarrollo en el sistema de haciendas y se constituyeron como la principal producción durante el siglo XIX (Mata de López 2005). Hacia fines de dicha centuria y primera mitad del siglo XX la producción forrajera reemplaza la harinera como principal actividad, con la alfalfa como cultivo predominante, debido a la especialización de las haciendas en la producción y comercialización de ganado vacuno. De esta manera, Cachi se establece como zona de paso cordillerano en el comercio de ganado vacuno a Chile, Bolivia y Perú, y la producción agrícola entonces se centra en el cultivo de grandes extensiones de pasturas para abastecer el engorde de animales que llegaban de las provincias del sur previo al cruce de la cordillera (Lera 2005). Pasado el cuarto del siglo XX la comercialización ganadera decae (Manzanal 1995, Pais 2011) y se extienden diversos cultivos orientados en gran parte al autoconsumo como variedades de cereales y frutales; y se instala el pimiento para pimentón como producción comercial alternativa
(Manzanal 1995, Marinangeli, Plastiné Pujadas y Páez 2016).

\section{Estructura agraria y formas de tenencia de la tierra}

Si bien en la década de 1950 alrededor de cien familias de arrendadores accedieron a la propiedad de la tierra a partir de la expropiación de la Finca Hacienda de Cachi (Lera 2005, Pais 2011); la configuración actual de la estructura agraria de la zona da cuenta de una polarización en la que se encuentran los grandes propietarios de los recursos -concentrados en pocos dueños- por un lado, y la población rural por otro (Arqueros y Manzanal 2004). El último Censo Nacional Agropecuario -CNA- realizado en forma completa en 2002 expresa que, del total de explotaciones con límites definidos, el $73 \%$ cuenta con menos de 5 hectáreas, mientras que las unidades productivas de hasta 10 hectáreas contemplan 93\% del total del departamento. Por otra parte, se registran grandes fincas de más de 10.000 hectáreas que comprenden el $89 \%$ de la superficie productiva (Marinangeli, Páez, Cieza y Plastiné Pujadas 2016). Asimismo, cerca de la mitad $-40 \%$ - de las explotaciones agropecuarias de Cachi presentan límites no definidos (CNA 2002), es decir, que no se puede registrar la cantidad de hectáreas que las componen y en general corresponden a “...los ocupantes de tierras privadas y fiscales; campos comuneros; aparcerías precarias y sucesiones indivisas, donde el campesinado constituye el principal poblador" (Paz y Jara 2014:86).

Esta inequidad se acrecienta teniendo en cuenta el incremento del proceso de concentración del territorio en los últimos años en el Noroeste Argentino (Obschatko et al. 2007). Las deficiencias estructurales de la distribución de tierras que ocupan los pequeños productores tienen que ver con entregas precarias de propiedad, arrendamientos a largo plazo, procesos de ocupación no resueltos o casos en los que la superficie concedida a partir del fraccionamiento de grandes predios es inferior a la unidad económica necesaria para dar sustento a la familia (García y Rofman 2009). Esto se profundiza cada vez más con los nuevos actores y actividades económicas presentes.

En cuanto a las explotaciones con límites definidos, a partir de distintos autores que trabajan en el valle y las categorías establecidas en los censos agropecuarios, se delimitan tres formas 
principales de tenencia de la tierra en Cachi. Por un lado la propiedad de la misma, con sus distintas extensiones y situaciones respecto de los títulos de propiedad, sucesiones familiares, etc. Por otro lado describen la mediería, que consiste en un acuerdo en el que el productor se encarga de las labores productivas, y al momento de la cosecha entrega la mitad de su producción al propietario a cambio de recibir la tierra lista para cultivar (Cieza 2010, Manzanal 1987). Finalmente, el arrendamiento se trata de un contrato en donde el productor paga el arriendo por el uso de la tierra para producir. Dicho pago al propietario puede ser monetario o con parte de la producción, y otra forma consiste en prestar mano de obra por una cantidad de días al patrón (Manzanal 1987). En este sentido, Cieza (2010) diferencia para el valle Calchaquí la figura del arrendero de la del arrendatario.

Los arrenderos se caracterizan por ser productores de subsistencia en el interior de unidades territoriales mayores: las fincas. La forma de pago de los arriendos es mediante el trabajo en estas explotaciones. Los arrendatarios explotan una determinada extensión de tierra bajo contrato -formal o informal-mediante el pago a su propietario de una cantidad determinada en dinero o especies (Cieza 2010: 36).

Si bien en la actualidad son frecuentes los arrendatarios, el "trabajo para el patrón" -como mencionan los interlocutores- como arrendero ha sido una constante en la configuración social de la región y es por tanto central para comprender los procesos sociohistóricos del valle (Villagrán 2014).

La relación entre "la finca", "los patrones" y "los peones" está atravesada por vínculos personales de compromisos y obligaciones que se establecen entre los propietarios de la tierra y quienes trabajan para ellos en relación de dependencia y, por tanto, desde posiciones diferenciales de poder (Villagrán 2014). Lanusse (2007) en su caracterización del trabajo en las fincas salteñas cita una ley provincial que sostiene que "...los arrenderos deben trabajar diecisiete días en las tierras del propietario de la finca a cambio de medio jornal, los aportes previsionales y el salario familiar correspondiente" (Lanusse 2007: 72). Sin embargo, la autora plantea que al menos en las primeras décadas del siglo veinte no se aplicaba y para la finca de Palermo la situación previsional de los arrenderos se regularizó con el gobierno del presidente Perón (1946-1952). Asimismo, en Cachi era habitual el empleo de la fuerza de trabajo de los productores familiares por parte de los patrones de las grandes haciendas para la producción de sus cultivos de renta, así como las labores domésticas -cocina, lavado y planchado de ropa, etc.-, que realizaban las mujeres. Así, las personas de mayor edad rememoran de igual manera que los patrones accedieron a otorgar mejores condiciones laborales y aportes para su jubilación a partir del estatuto del Peón Rural de Perón en 1944, pero en principio el pago por su fuerza de trabajo era retribuido con parte de la producción, y luego en dinero. Sostienen que contaban con un espacio en la finca para que construyeran su vivienda y establecieran su producción para autoconsumo, de la que muchas veces obtenían excedentes que le "vendían" al patrón -las comillas son nuestras y remarcan lo sugestivo del término, ya que seguramente esta entrega de productos conllevaba prácticas de explotación propias de sus posiciones desiguales de poder-. En este sentido, el poder y la autoridad que imponían estas figuras se pone de manifiesto en las expresiones de respeto y el distanciamiento con el que se habla de los patrones así como otras en las que sostienen que "el patrón me ha dejado hacer la casa" (M., 70 años, productora de Buena Vista), "me ha enseñado a trabajar la tierra" (J., 84 años, productora de Fuerte Alto), e incluso una persona rememora haber "tenido suerte, el patrón ha de cumplir, ha pagado vacaciones, ayuda para los hijos, he podido hacer mi casa" (J., 74 años, productor de Cachi Adentro). Pais (2011) visibiliza esta situación, propia de las haciendas y fincas en la actualidad, a partir de la referencia a prácticas clientelares, porque con frecuencia el antiguo patrón es en la actualidad una figura con poder político en la región. Así, "los arrenderos dependen del patrón no solo para seguir disponiendo de una parcela, sino también para la percepción de beneficios sociales que brinda el Estado y que se canaliza a través del poder político" (Pais 2011:168).

Estas formas históricas de acceder a la tierra aún siguen vigentes con sus diversos matices en los valles. De acuerdo con los tipos de tenencia mencionados con anterioridad, en Cachi 64,6\% de las explotaciones agropecuarias se encuentra en propiedad, mientras que $20,2 \%$ en arrendamiento y mediería, y 4,3\% combinan tierra en propiedad con arrendamiento y mediería (CNA 2002). Es importante destacar que estas estimaciones se realizan en las 416 explotaciones agropecuarias con límites definidos del departamento, mientras que de las 
264 sin límites definidos -con mayor presencia de pequeños productores- no es posible establecer la diferenciación. En la actualidad, algunos productores residen en las casas de los arriendos con el temor a ser desalojados por los herederos de sus patrones, actuales propietarios de las tierras. Otros en cambio, han obtenido su propiedad al venderse o expropiarse las antiguas haciendas en las que trabajaban, o han podido obtener su tierra por fuera de estos espacios que en general no excede las diez hectáreas como máximo -aunque es frecuente que no tengan los títulos de las tierras o bien estos estén en una situación irregular-(Marinangeli, Páez, Cieza y Plastiné Pujadas 2016; Pais 2011).

\section{El impacto de los cultivos de renta en la organización agrícola con posterioridad a la década de 1940}

Las prácticas agrícolas de la unidad productiva familiar en la actualidad están dirigidas tanto hacia los cultivos de autoconsumo como a los de renta $\mathrm{y}$ adquieren diversas configuraciones de acuerdo principalmente con el grado de irrupción que hayan tenido actores como el mercado y el Estado y su articulación con las configuraciones locales.

La siembra orientada al autoconsumo históricamente ha sido producida en las tierras que les otorgaba el dueño de la propiedad o patrón, a cambio de prestar servicios en la hacienda, y en la actualidad se colocan tanto en los campos de cultivo o rastrojos, donde también se producen los cultivos de renta, así como en las huertas asociadas a sus viviendas. Hay una gran diversidad de cultivos con los que abastecen el consumo familiar, como acelga, tomate, zanahoria, cebolla, lechuga, zapallo, haba, arveja, frutales, etc., e incluso aromáticas y plantas medicinales. El trigo, la papa y el maíz han tenido mayor preponderancia y son los cultivos que se rememoran con mayor asiduidad, tanto por la organización colectiva que requerían para su cultivo, la conservación, selección y reutilización de semillas, elaboración de comidas y bebidas tradicionales y el uso de las mismas para distintas ocasiones, entre las que se caracterizan el carnaval y la veneración a la Pachamama. En las festividades actuales (ferias gastronómicas, festivales, fiestas patronales, etc.) están presentes tanto dichos cultivos como las elaboraciones que producen con los mismos -locro, mazamorra, frangollos, chicha, papas para el asado, etc.-, por lo que se representan parte de "las costumbres", generando un lazo identitario muy estrecho tanto con lo que se produce como con las prácticas cotidianas que conlleva.

Hace algunas décadas, en caso de obtener excedentes en los cultivos de autoconsumo se intercambiaba con el patrón. En cambio, en el presente se comercializa principalmente en ferias de temporada o almacenes locales; algunos productos son llevados al mercado de Salta y, en otros casos, se intercambia con familia, vecinos o amigos en forma de préstamos, convidos o trueques. Estas últimas formas de intercambio provienen de prácticas ancestrales propias de formas comunales locales en las que la reciprocidad y la cooperación son la base organizativa, que hasta hace unos años hacía posible que las familias cuenten con todo lo necesario. Como mencionan las personas de mayor edad, antes "no se veían tantos pesos" (M., 84 años, productora de Payogasta), costaba ir a Salta o aún a los pueblos, y tampoco era común que hubiera panaderías, carnicerías, etc. La ruta 40 agilizó la comercialización de productos pero hasta mediados de siglo XX el abastecimiento local, o a una escala regional restringida, representaba la principal forma de satisfacción de las necesidades de la población. Solían contar con gran variedad de cultivos y animales para consumo -ovejas, cabras, vacas, gallinas-, intercambiaban telas para confeccionar su vestimenta y molían los granos para hacer la harina en los distintos molinos de la región. Por su parte, en momentos específicos de los ciclos del cultivo de autoconsumo, las familias se reunían para ayudarse, retribuyendo la colaboración unas con otras. En este sentido, se mencionan como torna a los intercambios de trabajo, así como a los préstamos de agua para riego. En esta dinámica se repartían labores y se compartía el día, además de, por ejemplo, llevarse cada familia parte de lo que se cosechaba. En estas ocasiones, al rememorar dichas prácticas, las personas suelen mencionar que "era más lindo porque éramos más unidos; la gente se ayudaba más, compartía y era más desinteresada" (N., 52 años, productora de Cachi Adentro); mientras que en la actualidad remarcan prácticas más individualistas, siendo que a cada uno le interesa "poner y trabajar para sí mismo" (R., 63 años, productor de San José). Esto inclusive se pone de manifiesto en los intercambios actuales, en los que rige principalmente un valor de cambio establecido por el mercado que la equivalencia por cantidad de peso. Así, "antes decías vamos a 
cambalachear, te doy 5 kilos de maíz dame 5 kilos de arvejas, ahora ya casi todo va por el precio. La arveja vale más así que si cambiás 5 kilos de maíz te dan 3 de arvejas, depende de cada uno" (M., 57 años, productora de Las Trancas).

Estas intromisiones propias de lógicas de mercado en la organización agrícola familiar han ido en incremento. Uno de los hitos de mayor trascendencia en esta dirección tiene que ver con la introducción del pimiento para pimentón como cultivo de renta, desplazando en proporción a cultivos tradicionales como la papa, el trigo y el maíz en sus distintas variedades (Marinangeli, Plastiné Pujadas y Páez 2016). Así, las primeras referencias censales de este cultivo en el departamento de Cachi datan de 1937 -una sola explotación de 2 hectáreas- (Ministerio de Agricultura 1939), que de acuerdo con los entrevistados habría sido iniciativa de patrones de fincas asentadas en los alrededores de Payogasta para introducir un cultivo de renta proveniente de Rosario de Lerma que reemplazara la producción de alfalfa, y que obtuvo gran difusión entre los grandes finqueros de la región por los rindes exitosos que otorgaba. A partir de allí, el pimiento para pimentón adquiere gran desarrollo y extensión en todo el Valle Calchaquí, convirtiéndose en el principal cultivo comercial (Arqueros y Manzanal 2004; Cieza 2010; Frere 2004; Manzanal 1987; Pais 2011) y posicionando al área como la principal productora de pimentón del país (Cieza 2010).

La participación de los productores familiares en el circuito mercantil con el cultivo de pimiento para pimentón está asociada, como se explicitó anteriormente, a las condiciones de acceso a la propiedad de la tierra con la expropiación de la Finca Hacienda de Cachi en 1949. De esta manera, los antiguos arrenderos comenzaron a comercializar de manera directa el pimiento con los intermediarios que se acercaban a comprarlo o con los propietarios de las fincas, pero buscando obtener dinero para poder abonar la compra de las pequeñas parcelas adquiridas luego de la expropiación. Para mediados de siglo XX Cachi había logrado una mayor articulación con el mercado regional, lo que se vio favorecido por la construcción de la ruta 40, posibilitando la afluencia de nuevos actores y productos en el escenario local.

Esta actividad de renta conlleva una especialización productiva, al margen que se sostengan los cultivos de autoconsumo, y otras dinámicas organizativas y de labranza. Entre ellas, al convertirse en un monocultivo y sembrar rastrojos enteros con pimiento, se comenzó a intensificar el uso de agroquímicos. Si bien los interlocutores recuerdan utilizar algún "matayuyo" o fertilizante, mencionan que lo más común era desyerbar manualmente y emplear abonos naturales como el guano de cabra para el resto de los cultivos. En la actualidad incluso al maíz le colocan "remedios" para que no lo ataquen los pulgones, gusanos y "otras pestes" que antes "no se conocían". Sin embargo, otras personas realizan una distinción en su uso solo para los cultivos de renta pero no para los de autoconsumo porque "contamina", "le quitan fuerza a la tierra", etc. Esta apelación a lo "natural", en cambio, puede verse reflejada en asociación a la rotación de cultivos, cuando la producción de renta principal se detiene por alrededor de 3 años, sembrando alfalfa en el rastrojo durante ese período para que reponga los nutrientes y quede la "tierra nueva".

El pimiento también requiere una mayor mecanización -que agiliza los tiempos pero a su vez aumenta los costos- principalmente para la preparación del suelo, en lugar de herramientas más manuales o de tracción a sangre con las que realizaban la labranza anteriormente. La inversión de trabajo también ha tenido que ser mayor, comprometiendo a gran parte del núcleo familiar. Si bien la mujer siempre trabajó en la agricultura, antes era más común que se dedicara a las tareas domésticas y al cuidado de los animales o la huerta en la vivienda, mientras que en la actualidad "es brava: sale a carpir, a sembrar, a trabajar con el marido en el rastrojo". Algunas personas comentan también que, en esta época de crisis, las tornas, trueques y el trabajo de toda la familia está volviendo porque no se puede pagar peones, y con los intercambios se aseguran de abastecerse de los alimentos necesarios.

El mayor individualismo al que hacen referencia los entrevistados tiene que ver también con las condiciones de comercialización, ya que los productores deben acordar los precios con los intermediarios que llegan a comprarles el pimiento, aceptando muchas veces el precio que los mismos les imponen. En este sentido, adjudican responsabilidad al Estado, siendo que a pesar de los programas que intentan implementar para que accedan por ejemplo a subsidios, los agricultores familiares no concretan organizaciones donde se concentren como productores para obtener mejores negociaciones, agregarle valor al pimiento para evitar venderlo a granel que es cuando menos se lo pagan, etc. Si 
bien tienen presente en su mayoría lo beneficioso que resultaría unirse entre ellos, también refieren un "trabajo sistemático del gobierno para fomentar el individualismo y enfrentarse entre vecinos" (R., 70 años, productor de Cachi Adentro, 2017), y rememoran una ingrata experiencia con una cooperativa que se fundó en la década de 1980.

Además del pimiento para pimentón como producción principal de renta, también se cultiva cebolla, tomate platense, poroto -según la zona-, arvejas, alfalfa, zanahoria y otras verduras de estación que circulan a nivel más local, mientras las producciones principales tienen como destino la ciudad de Salta, y algunas se exportan por Jujuy o Buenos Aires. A este tipo de cultivos se refieren los interlocutores cuando se consulta por la "producción", mientras que muchos productores familiares cuentan con cultivos de autoconsumo en las huertas de sus viviendas y no los mencionan como tales sino que "son para consumo de la casa nada más". Esta diferenciación, junto con las definidas anteriormente respecto de la organización de sus formas de labranza, guarda relación con algunas formas ancestrales de conceptualizar la naturaleza, ajena a las lógicas instrumentalistas y en vinculación con los ciclos naturales y su relación con la crianza de seres vivos. La veneración a la Pachamama por ejemplo, da cuenta de la importancia de esta creencia en el desarrollo de las lógicas productivas locales (Plastiné y Páez 2018).

\section{El impacto del mercado con posterioridad a la década de 1970}

A partir del año 2000, la profundización de las políticas neoliberales implementadas en el país tuvo un impacto directo en la configuración parcelaria de Cachi, en particular teniendo en cuenta las características ambientales de la región para favorecer ciertos cultivos, y las políticas para favorecer el turismo, tanto desde el sector público como el privado. La acentuación de la actividad vitivinícola y el incremento del valor de la tierra en relación con la especulación inmobiliaria incentivada por las inversiones hoteleras, gastronómicas, etc., vinculadas al turismo, contribuyen al proceso de concentración de tierra -en gran parte en manos de capitales extranjeros- e imposibilitan aún más el acceso a la propiedad por parte de los pequeños productores agropecuarios. Manzanal (1995) adjudica el inicio de este proceso a las políticas liberales implantadas en el país a partir de la década de 1970, que tuvieron como consecuencia una reestructuración parcelaria en la que los pequeños productores minifundistas vendieron o entregaron parcelas ${ }^{4} \mathrm{de}$ su tierra a productores de gran poder económico que las concentraron. Esto es una limitante muy importante en la estructura agraria de la región, que los productores lo ponen en términos de las "desventajas de partida" que tienen que afrontar en su actividad productiva.

Por otro lado, a partir de la primera década del siglo XXI se extienden en Cachi numerosos emprendimientos vitivinícolas de capitales extranjeros, orientados a producir vinos de altura. Si bien la presencia de los cultivos de vid en los valles calchaquíes salteños es histórica y proviene de su instauración en las grandes haciendas, ha sido el vecino departamento de Cafayate quien ha concentrado alrededor del $70 \%$ del total de la producción de vid de la provincia (Manzanal 1995). Para Cachi, en 1937 se registran 20 explotaciones de vid destinada a uva para mesa y a uva para pasa (Marinangeli, Páez, Cieza y Plastiné Pujadas 2016) y actualmente también es frecuente que los pobladores produzcan sus propios vinos, la fruta fresca o pasas, tanto para consumo como para venta (Pais 2011). La elaboración de vinos de los pequeños productores, además de la escala de producción, se caracteriza por determinado tipo de uva, las técnicas de elaboración tradicional, vínculo con la tierra y su elaboración, etc., frente al manejo industrial de los nuevos emprendimientos instalados en los últimos años (López et al. 2012). De esta manera, en Cachi la actividad se ha vuelto más significativa en consonancia con la compra de grandes extensiones de tierras para el establecimiento de las bodegas, profundizando el impacto en la concentración parcelaria y en las formas de explotación que conlleva esta producción de características industriales. Así, en estos establecimientos se implementan nuevas variedades de uva, riego por goteo y se introducen tecnologías que no se utilizaban en el departamento. En este caso, si bien la mayoría de los entrevistados da cuenta del proceso de concentración de tierra en manos extranjeras -suizos, noruegos, franceses, chilenos-, y advierten que ya no pueden utilizar el espacio comunal de esas tierras para adquirir leña o pastar animales porque son propiedad privada, ven en estas explotaciones la oportunidad laboral como fuente de trabajo, aunque también 
atribuyen en algunos casos - cerca de Payogasta, por ejemplo- la merma en el acceso al agua por el acaparamiento para esta actividad.

Villagrán (2013) expresa que Cafayate se posiciona hacia la década de 1970 como un importante destino turístico cuyo atractivo principal es el vino, y que en los 90 toma un nuevo impulso a causa de la reconversión productiva y la comercialización del vino y el turismo a nivel internacional, promocionándose desde políticas de turismo provinciales. Es desde mediados de esta década donde la autora encuentra que gran parte de las fincas orientadas a la producción de vid en Cafayate fueron vendidas a capitales extranjeros, y la gente del lugar sufrió por tanto la expulsión y se vio imposibilitada de acceder a las tierras y contratos que establecían con los antiguos propietarios, proceso similar al planteado anteriormente con la extranjerización de la tierra en Cachi.

La promoción del turismo ha registrado un aumento de la actividad a partir de fines de 1990, vinculado a una estrategia por parte del gobierno provincial de promocionar su historia, la naturaleza y la cultura de la población del lugar (Pais 2011). En este marco se encuentra el recorrido de "La ruta del vino", que vincula vino y turismo a partir de un circuito propuesto y promocionado por el gobierno provincial y cámaras empresariales de la actividad enoturística, articulando las principales bodegas de altura del valle calchaquí y el turismo, por medio de sus "pueblos centenarios con una enorme riqueza cultural que se expresa en su música y artesanía" (sitio oficial de turismo del gobierno de la provincia de Salta 2018). Así lo promocionaba en su momento la subsecretaría de Desarrollo del Ministerio de Cultura y Turismo provincial en un medio periodístico: "Para nosotros la Ruta del Vino es uno de nuestros productos turísticos emblema para promocionar Salta... Posiciona al paisaje y la cultura como atractivos muy fuertes y auténticos". Asociado a ello, se ha invertido en infraestructura vial, y se establecieron restaurantes, hoteles, negocios de artesanías y regionales que generaron expectativas de trabajo entre los pobladores. Sin embargo, y a pesar de las perspectivas no generan una cantidad significativa de empleo, en especial para el sector rural en el que sí han repercutido otras consecuencias como el aumento en el precio de la tierra, compra de las superficies ocupadas por los pobladores locales, cambios en el uso de la tierra, etc. (Pais 2011).
Cachi es el único pueblo salteño incluido en el Programa de Pueblos Auténticos impulsado por el Ministerio de Cultura y el Ministerio de Turismo de la Nación para promover su desarrollo turístico y que sea por tanto una herramienta de desarrollo cultural que procure "revalorizar la identidad de pequeños pueblos, promoviendo la apropiación de la comunidad local y la revalorización del patrimonio natural y cultural" (Secretaría de Turismo de la Nación, 2017). En este marco, se intenta poner de relieve su pintoresca cultura, historia e identidad, realzando sus características coloniales y pasado indígena -generando por tanto un distanciamiento con los pueblos indígenas actuales- (Castellanos et al. 2018).

Los cambios en la configuración territorial producto del avance, tanto del turismo como de los emprendimientos vitivinícolas han generado un impacto en la población local. En algunos casos, esto ha significado la venta de terrenos que eran usados para la agricultura, lo que ha devenido en que o bien tuvieran que arrendar para seguir desarrollando la actividad, o bien tuvieran que cambiar su lugar de residencia migrando a las metrópolis cercanas. En otros casos, se ha avanzado sobre territorios de los pueblos originarios, motivando violentas acciones de desalojo que, en el caso de no prosperar, condicionaron la forma en que se desarrolló la actividad económica de allí en más. Al respecto, los pobladores de Las Pailas que resistieron un intento de desalojo en el 2010, estuvieron mucho tiempo sin cultivar sus chacras o criando un número reducido de ganado caprino frente al temor de que las experiencias vividas se reprodujeran nuevamente. Los territorios de pastoreo también representan otro foco de controversia, porque su utilización es fundamental para sostener la vida económica de un sector importante de los habitantes que, por su parte, provee de carne y derivados de la leche a otros sectores de la población.

Por otro lado, la pérdida de la propiedad colectiva de los medios de producción ha dado lugar a manifestaciones cada vez más conspicuas del individualismo como forma de organización social y laboral. El uso de "lo tradicional" ya no es posible ni rentable en un contexto en el que las nociones de tiempo y trabajo responden a las lógicas modernas. De este modo, la fractura en el tejido comunitario se muestra como un escenario favorable para el avance de los sectores con mayor concentración de capital económico. 


\section{Discusión y conclusiones}

La limitación en el acceso a la propiedad de la tierra ha sido un condicionante histórico para las poblaciones productoras del Valle Calchaquí. El despojo de los territorios sostenido en distintas estrategias, coercitivas o disuasivas, ha ido desarmando las formas colectivas de organización del trabajo agrícola, con la consecuente pérdida de autonomía y el posicionamiento de una figura de poder, el patrón. Estas lógicas, que tomaron forma muy tempranamente en la población local, se fueron naturalizando, dando lugar a vínculos contractuales abusivos, muchas veces aceptados sin resistencia.

El avance del mercado, que aquí hemos analizado a partir de la década de 1940 por la importancia del pimiento para pimentón en la región, se ha valido de estas estructuras de poder preexistentes. El cultivo de esta especie representa la forma de inserción de la población local en el mercado hortícola regional, formando parte de una cadena de comercialización en donde el precio pagado a los productores locales dista notablemente de los valores en los que el producto se inserta en los mercados nacionales e internacionales. En este sentido, la falta de estructuras corporativas atenta contra la posibilidad de lograr precios más justos, en tanto los compradores arreglan los valores con los productores individualmente, por lo que se instala la competencia como el principal mecanismo de colocación del producto, sujeto asimismo al requerimiento de diversos insumos que aumentan los costos productivos.

En las últimas décadas, la profundización del modelo neoliberal en el país ha exacerbado la ferocidad del mercado, abarcando diferentes productos cultivados en el valle, además de generar grandes reconfiguraciones en la estructura parcelaria a partir de una mayor concentración de territorio en un sector minoritario de la población. La consolidación de inversiones extranjeras orientadas al turismo y la industria vitivinícola ha significado la pérdida de territorios comunales, así como de aquellos que, mediante diferentes formas contractuales, eran utilizados por los pequeños productores para el cultivo.

La respuesta de parte de la sociedad a estas políticas que profundizan la ya existente inequidad en el acceso a los recursos se relacionan, por un lado, con la organización en defensa de su territorio amparados por mecanismos otorgados por el Estado Nacional como es la Ley 26160 que contempla "la emergencia en materia de posesión y propiedad de las tierras que tradicionalmente ocupan las comunidades originarias del país", sancionada en el 2006. Por otro lado, es posible identificar las estrategias sostenidas de las formas de intercambio tradicionales como las tornas en algunos casos, préstamos, convidos y el trueque, aunque en estos casos, las formas de cambio ya no obedecen a los principios de necesidad, sino al valor en moneda que tiene cada producto cambiado, o aún, la autogestión de los recursos culturales devenidos en bienes turísticos. La acción política y la organización comunitaria se presentan, entonces, como la alternativa más eficaz en defensa de las perspectivas locales en torno a las prácticas agrícolas, así como a la manera de vivir y habitar el territorio.

\section{Agradecimientos}

A los pobladores del departamento de Cachi y cada uno de los entrevistados y colaboradores que han permitido desarrollar este trabajo. A Sara, Catalina y demás compañeros de equipo. A las instituciones que hacen posible el financiamiento para los trabajos de campo al Consejo Nacional de Investigaciones Científicas y Técnicas y la Agencia de Promoción Científica y Tecnológica de Argentina. A los evaluadores por sus consideraciones y aportes.

\section{Referencias Citadas}

\footnotetext{
Arqueros, M. X. y M. Manzanal

2004 Interacciones y vinculaciones interinstitucionales para el desarrollo territorial-rural: el caso de San Carlos en Salta. Primeras Jornadas Interdisciplinarias de Estudios Agrarios y Agroindustriales del NOA, Salta.

Baldini, L. y V. Villamayor

2007 Espacios productivos en la cuenca del rio Molinos (Valle Calchaquí, Salta).Cuadernos de la Facultad de Ciencias Sociales(32):35-51.
}

Cáceres, C.

2018 "Sofisticación territorial y turismo enológico en Salta: desavenencias en el Valle Calchaquí'. Revista del Departamento de Geografía FFyH-UNC-6 (10): 285-317.

Cáceres, C. y C. Troncoso

2014 Turismo, territorio y transformaciones recientes en los Valles Calchaquíes Salteños. Cuando el territorio se (re) valoriza con fines turísticos. Actas I Jornadas de Investigación y Gestión en el Valle Calchaquí (Salta): 7-21. 
Carballo A., G. Bramuglia, C. Gras, J. Plano, C. Rossiy P. Tsakoumagkos

2004 Articulación de los pequeños productores con el mercado: limitantes y propuestas para superarlas. Ministerio de Economía y Producción. Secretaría de Agricultura, Ganadería, Pesca y Alimentos, Dirección de Desarrollo Agropecuario. Serie Estudios e Investigaciones PROINDER $\mathrm{N}^{\circ} 7$.

Castellanos, M.C.

2016 "El Valle Calchaquí Medio (Salta, Argentina) durante los siglos XV-XVII: aportes desde el registro arqueológico y las fuentes documentales". Diálogo Andino 49: 273-286.

Castellanos, M.C., P. Lanusse., L. Rodríguez, M.V. Sabio Collado, A.J. Villagrán

2018 "Los Valles Calchaquíes y los Diaguitas: procesos históricos, desigualdades y disputas identitarias". Voces en el Fénix 8 (72): 22-29.

Censo Nacional Agropecuario

1988 INDEC. http://www.indec.gob.ar/nivel4_default. asp?id_tema_1=3\&id_tema_2 $=8 \&$ id_tema_3=87 (1 de julio de 2016).

Censo Nacional Agropecuario

2002 INDEC. http://www.indec.mecon.gov.ar/agropecuario/ cna2.asp (1 de julio de 2016).

Cieza, G.

2010 Procesos Organizativos y Acceso a la Tierra en el Valle Calchaquí. Tesis para optar por el título de Doctor en Ciencias Agrarias, Universidad Nacional de La Plata, Argentina.

Díaz, P.P.

1983 "Sitios Arqueológicos del Valle Calchaquí". Estudios de Arqueología 3-4: 93-104.

Dirección General de Estadísticas de Salta.

2013 Anuario Estadístico Provincia de Salta: Año 2012-Avance 2013. http://estadisticas.salta.gov.ar/anuarios-estadisticos (30 de agosto de 2015).

Frere, $\mathrm{P}$.

2004 Consultoría: Diagnóstico sobre la población objetivo de las políticas de desarrollo rural de la Provincia de Salta. Ministerio de Economía y Producción Secretaría de Agricultura, Ganadería, Pesca y Alimentos Dirección de Desarrollo Agropecuario. PROINDER.http://redaf.org.ar/ wp-content/uploads/2012/12/Diagnostico_poblacion-objetivoSalta_desarrollo-rural-Frere-2004.pdf(15 de octubre de 2015)

García, A. y A. Rofman

2009 "Agrobusiness y fragmentación en el agro argentino: Desde la marginación hacia una propuesta alternativa" (11 de mayo) Mundo agrario 10 (19). http://www.mundoagrario. unlp.edu.ar/ (2 de Abril 2016).

Guber, $\mathrm{R}$.

2001 La etnografía, método, campo y reflexividad. Grupo Editorial Norma, Bogotá, Colombia.

Hocsman, L.

2003 Estructura Rural,Territorialidad y Estrategias Domésticas en la Cordillera Oriental (San Isidro, Finca El Potrero-Colanzuli, Finca Santiago, Salta). Tesis para optar por el título de Doctor en Ciencias Naturales,Universidad Nacional de La Plata, La Plata, Argentina.

INTA

2008 Zonas agroeconómicas homogéneas: Salta-Jujuy. Estudios socio-económicos de la sustentabilidad de los sistemas de producción y recursos naturales. $\mathrm{N}^{\circ} 7$.
Lanusse, $\mathrm{P}$.

2007 Memorias y Alteridades Indígenas en Cachi, Provincia de Salta. Tesis para optar por el título de Licenciatura en Antropología, Universidad de Buenos Aires, Buenos Aires, Argentina.

Lera, $M$.

2005 Transformaciones Sociales y Económicas en Cachi a Fines del Siglo XIX. Tesis para optar por el título de Licenciatura en Antropología, Universidad Nacional de Salta, Salta, Argentina.

Llambí, L.

1981 "Las unidades de producción en un intento de teorización”. Estudios Rurales Latinoamericanos 4 (2):121-153.

Lorandi, A.M. y R.Boixadós

1987-1988 "Etnohistoria de los valles calchaquíes en los siglos XVI y XVII". Runa XVII- XVIII:263-419.

López, O.; A. Muller y E. Abdo

2012 Agricultura Familiar y elaboración de vino en los Valles Calchaquíes. Organización y transformaciones. Asociación Argentina de Extensión Rural http://aader.org.ar/XVI_jornada/trabajos/archivos/2012/271_trabajo_atm_muller.pdf (15 de Noviembre de 2017).

Manzanal, M.

1987 Pobreza y marginalidad en el Agro Argentino: la producción agrícola y su comercialización en Cachi, Salta. Centro de Estudios Urbanos y Regionales, Buenos Aires, Argentina.

Manzanal, M.

1995 "Globalización y ajuste en la realidad regional argentina: ¿reestructuración o difusión de la pobreza?”. Realidad Económica 134:67-82.

Marinangeli, G.; I. Plastiné Pujadas y M.C. Páez

2016 Aproximación a las transformaciones productivas en el norte del Valle Calchaquí (depto. de Cachi, Salta). Actas de las VIII Jornadas de Investigación en Antropología Social Santiago Wallace:1987-1997. Universidad de Buenos Aires.

Marinangeli, G.; M.C. Páez; R. Cieza e I. Plastiné Pujadas 2016 Organización de la producción y distribución de cultivos en el norte del Valle Calchaquí. Actas del VI Congreso Argentino y Latinoamericano de Antropología Rural. Universidad de Salta, Salta.

Mata de López, S.

2005 Tierra y poder en Salta: El noroeste argentino en vísperas de la independencia. CEPIHA, Salta, Argentina.

Mayer, E.

2004 "Cultura, mercados y economías campesinas en los Andes”. Revista de Antropología 2 (2):47-78.

Ministerio de Educación, Ciencia y Tecnología

2014 Mapa Educativo Provincial. Gobierno de la Provincia de Salta, Salta. http://www.edusalta.gov.ar/index.php/201405-09-13-50-01/2014-05-06-13-18-52/mapa-educativo (4 de abril de 2018).

Ministerio de Agricultura de la República Argentina 1939 Censo Nacional Agropecuario año 1937. Kraft, Buenos Aires.

Obschatko, E. Scheinkerman de; M.P. Foti y M. Román 2007 Los pequeños productores en la República Argentina: importancia en la producción agropecuaria y en el empleo en base al Censo Nacional Agropecuario 2002. 2da ed. Serie Estudios e Investigaciones (10). 
Páez, M. C.; M. Giovannettiy R. Raffino

2012 "Las Pailas. Nuevos aportes para la comprensión de la agricultura prehispánica en el Valle Calchaquí Norte (provincia de Salta)". Revista Española de Antropología Americana 42 (2):339-357.

Páez, M. C.; V. Lynch e Y. Besa

2014 "Espacios sagrados en el mundo andino: excavación de una huanca en Las Pailas (Cachi, Salta, Argentina)". Revista Española de Antropología Americana 44 (1):275-284.

Páez, M.C. y M. Giovannetti

2014 "Canales aéreos y subterráneos de Las Pailas (Cachi, Salta). Aproximaciones al estudio de la red hidráulica". Estudios Antropología-Historia, Nueva Serie 2: 9-121.

Páez, M.C. y L. López

2016 La tecnología hidráulica del Valle Calchaquí Norte (Cachi, Salta). La tecnología hidráulica del Valle Calchaquí Norte (Cachi, Salta). Actas del XIX Congreso Nacional de Arqueología Argentina: 1977-1985. Universidad Nacional de Tucumán.

Pais, A.

2011 Las Transformaciones en las Estrategias de Reproducción Campesinas en Tiempos de Globalización. El caso de Cachi en los Valles Calchaquíes. Tesis para optar por el título de Doctor en Ciencias Agropecuarias, Universidad Nacional de Córdoba, Argentina.

Paz, R. y C. Jara

2014 "Estructura agraria en Santiago del Estero: el proceso de territorialización de las explotaciones campesinas sin límites definidos y su tensión frente al avance del capitalismo agrario". Estudios rurales 1(6):81-99.

Plastiné Pujadas, I. y M.C. Páez

2018 "Mestizaje y resistencia en torno a la creencia en la Pachamama en el Valle Calchaquí Norte (Salta, Argentina)". Boletín de Antropología 57 (1). En prensa.

Prieto, M. E.; Y. Besa; G. Marinangeli; F. Riegler y M.C. Páez 2012 "Los campos agrícolas de Las Pailas (Cachi, Salta)". La Zaranda de Ideas (8):137-149.

Raffino, R. y L. Baldini

1983 "Sitios arqueológicos del Valle Calchaquí Medio (Depto. Molinos y San Carlos)". Estudios de Arqueología 3-4: 6-36.

Rock Núñez, M.E.

2016 "Memoria y Oralidad: formas de entender el pasado desde el presente". Diálogo Andino 49: 101-112.

Shanin, T.

1976 Naturaleza y Lógica de la Economía Campesina. Anagrama, Barcelona, España.

Tarragó, M.

1974 "Aspectos ecológicos y poblamiento prehispánico en el valle Calchaquí, provincia de Salta, Argentina". Revista del Instituto de Antropología 5: 195-216.
Tarrago, M.

1977 La localidad arqueológica de Las Pailas, Provincia de Salta, Argentina. Actas del VII Congreso de Arqueología de Chile, tomo 2, pp. 499-517.

Tarragó, M. y P.P. Díaz

1972 "Sitios Arqueológicos del Valle Calchaquî". Estudios de Arqueología 1: 49-62.

Tarragó, M. y M. de Lorenzi

1976 "Arqueología del Valle Calchaquí". Etnía 23-24:1-35.

Tsakoumagkos, P.; S. Soverna y C. Craviotti

2000 Campesinos y Pequeños Productores en las Regiones Agroeconómicas de Argentina. Ministerio de Economía, Secretaría de Agricultura, Ganadería, Pesca y Alimentación. Dirección de Desarrollo Agropecuario. PROINDER.

Vázquez, E.

2014 Vino, paisaje y cultura cotizan en el mercado global. El caso de la vitivinicultura en Cafayate. Actas del XI Congreso Argentino de Antropología Social, Rosario.

Vázquez, E. y M.A. Aguilar

2014 Vinos y "Estilos de vida" Transformaciones sociales en los Valles Calchaquíes. Actas del XI Congreso Argentino de Antropología Social, Rosario.

Villagrán, A.J.

2013 "El vino más alto y bajo el más bello cielo". Procesos de patrimonialización, turismo y estrategias empresariales. El caso de Cafayate (Valle Calchaquí), norte de Argentina. Vivência: Revista de Antropologia 1(42): 41-64.

Villagrán, A.J.

2014 “'La Finca', el tiempo y los eventos en Animaná. Un acercamiento al pasado-presente de los Valles Calchaquíes, Salta". Memoria Americana 22 (2): 147-182.

Turismo del Gobierno de la Provincia de Salta

2018 Recuperado el 11 de diciembre de 2018, de: http:// turismo.salta.gov.ar/contenido/71/ruta-del-vino

Secretaría de Turismo de la Nación

2017 Desarrollo turístico: se presentó el programa Pueblos Autóctonos. Recuperado el 11 de diciembre de 2018 , de: http://www.turismo.gov.ar/noticias/2017/10/30/ se-presento-programa-pueblos-autenticos

Williams, V.; M. A. Korstanje; P. Cuenya y M. P. Villegas

2011 "La Dimensión Social de la Producción Agrícola en un Sector del Valle Calchaquí Medio". En Arqueología de la Agricultura: Casos de Estudio en la Región Andina Argentina, editado por M.A. Korstanje y M. Quesada, pp. 178-207.Ediciones Magna, Tucumán, Argentina.

Williams, V. y C. Castellanos

2014 "Paisajes, materialidad y memoria social en el Valle Calchaquí Medio". Revista Escuela de Historia 13(2), 00. Recuperado el 11 de diciembre de 2018, de http://www.scielo.org.ar/scielo. php?script=sci_arttext\&pid=S1669-90412014000200004\&ln $\mathrm{g}=\mathrm{es} \& \ln \mathrm{l}=\mathrm{es}$.

\section{Notas}

1 Los trabajos de campo etnográficos han estado enfocados al tema de investigación de la tesis doctoral en curso de la primera autora que tiene lugar en la Universidad Nacional de La Plata y es dirigido por la segunda autora.

2 Se han realizado desde 2014 más de 30 entrevistas abiertas a pobladores de distintas edades y género del departamento de Cachi (Salta). En este sentido, hemos consultado acerca de los tipos y formas de producción agrícola, tenencia, distribución y conflictos de tierras, representaciones identitarias, factores que inciden en la organización productiva, aspectos rituales y festivos, etcétera.

3 Se establecieron alrededor de 20 entrevistas semiestructuradas orientadas a pequeños productores familiares, tanto mujeres como hombres entre 25 y 84 años que practican la 
agricultura en el departamento de Cachi (Cachi, Payogasta y distintos parajes rurales como Buena Vista, Cachi Adentro, Fuerte Alto, San José, etc.), profundizando en aspectos específicos de la organización de la producción, actores intervinientes, labores asociadas, circuito de comercialización o consumo, actividades comunales, relación de los productores con el Estado y otras instituciones como el mercado, etc. El registro de la memoria oral ha permitido acercarnos a la comprensión de las dimensiones culturales, espaciales y temporales de las representaciones de dicho grupo (Rock Nuñez 2016).

4 Los motivos están siendo indagados en la actualidad en el desarrollo de la tesis doctoral de una de las autoras. Es posible que la ausencia o precariedad de los títulos de propiedad en manos de pequeños productores, las ofertas de dinero y presiones que reciben para vender, la falta de acuerdos en las familias con las herencias de la propiedad, etc., sean factores que intervienen en la decisión. 
